\title{
Diagnostic accuracy of transcutaneous bilirubinometer devices compared with the total serum bilirubin measurement in preterm $(\leq 35$ weeks) very low birth weight neonates during the neonatal period up to 7 days of life
}

\author{
*Nawaz Zuberbhai Patel ${ }^{1}$, Sheila G Aiyer ${ }^{1}$ \\ Sri Lanka Journal of Child Health, 2020; 49(1): 23-29
}

\begin{abstract}
Introduction: Hyperbilirubinaemia is the commonest morbidity in preterm neonates, most of whom are of very low birthweight (VLBW $\leq 1500 \mathrm{~g}$ ) babies. Repeated blood sampling in preterm VLBW neonates not only causes pain but may lead to sepsis and anaemia. Transcutaneous measurement of bilirubin by a device called transcutaneous bilirubinometer (TcB) is an effective alternative tool to predict neonatal hyperbilirubinaemia in late preterm and term neonates, most of whom have birthweights $>2000 \mathrm{~g}$.
\end{abstract}

Objectives: To evaluate diagnostic accuracy of $\mathrm{TcB}$ devices in comparison to total serum bilirubin (TSB) measurements in VLBW neonates.

Method: We evaluated 128 preterm neonates with gestational ages ranging from 28 to 35 weeks and birthweights $\leq 1500 \mathrm{~g}$ till 7 days of post-natal age. A total of $1003 \mathrm{TcB}$ readings were taken, along with concurrent heel prick capillary samples, for laboratory measurement of TSB. For TcB, Drager JM-103 transcutaneous bilirubinometer was used and for TSB, Microlab's Easybil instrument was used. Coefficient of correlation (r) and BlandAltman plot were calculated to check correlation between TSB and TcB.

Results: Total number of neonates was divided into 2 groups: i) $\leq 1000 \mathrm{~g}$ and ii) 1001-1500g. Paired readings of TSB and TcB were taken before and after starting phototherapy. All the paired readings were analysed for correlation between $\mathrm{TcB}$ and TSB. Correlation co-efficient (r) value for group i) was 0.87 and for group ii) was $0.89(\mathrm{p}<0.0001)$. Before and after starting phototherapy, readings were analysed separately to see the effect of

${ }^{1}$ Government Medical College Baroda, India
*Correspondence: nawaz78692@gmail.com

(D) https://orcid.org/0000-0002-3140-891X

(Received on 04 May 2019: Accepted after revision on 21 June 2019)

The authors declare that there are no conflicts of interest

Personal funding was used for the project.

Open Access Article published under the

Commons Attribution CC-BY (C) (i) License phototherapy on correlation between TcB and TSB. Correlation co-efficient ( $r$ ) values for paired readings before starting phototherapy were $0.97 \&$ 0.90 respectively for both groups and for paired readings after starting phototherapy were $0.81 \&$ 0.83 respectively for both groups.

Conclusions: TcB measurements correlate significantly with TSB levels in early preterm neonates with VLBW. Phototherapy does not affect the correlation significantly.

DOI: http://dx.doi.org/10.4038/sljch.v49i1.8893

(Key words: Hyperbilirubinaemia, preterm neonate, transcutaneous bilirubin, VLBW)

\section{Introduction}

Preterm neonates are more at risk for hyperbilirubinaemia due to immature hepatic function, polycythaemia, delay in starting feeds, sepsis, etc. ${ }^{1,2}$. Hyperbilirubinaemia is potentially more dangerous in premature VLBW (birthweight $\leq 1500 \mathrm{~g}$ ) neonates due to the immature blood brain barrier which can lead to bilirubin induced neuronal damage ${ }^{3}$. Rough bilirubin estimation can be made visually as neonatal hyperbilirubinaemia progresses cephalocaudally ${ }^{3}$. However, recent studies showed that visual assessment correlates poorly with $\mathrm{SB}^{3,4,5}$. Blood sampling to estimate $\mathrm{SB}$ is the commonest investigation done in the neonatal intensive care unit (NICU) ${ }^{6}$. This is frequently performed by heel prick, a painful procedure with long-term sequelae. Therefore, an accurate noninvasive method of SB estimation is required. Transcutaneous estimation of bilirubin by a handheld device called transcutaneous bilirubinometer $(\mathrm{TcB})$ uses the principle of reflectance photometry and colorimetry ${ }^{7}$. TcB devices estimate SB by directing light into the neonatal skin and measuring the intensity of specific wavelengths ${ }^{7}$. There are several devices for transcutaneous estimation of bilirubin like "Bili Med", "Drager JM-102". "Drager JM-103", "Drager JM-105". We used "Drager JM-103" for current study. These devices correlated well with SB in term and near-term neonates in various studies ${ }^{1-2,8-10}$. Most neonates in these groups were of birthweight $>2000 \mathrm{~g}$. American Academy of Pediatrics recommends utilisation of TcB devices for evaluating jaundice in infants $>35$ weeks' gestation ${ }^{11}$. However, the 
accuracy of $\mathrm{TcB}$ devices for estimating $\mathrm{SB}$ in preterm ( $\leq 35$ weeks) VLBW neonates remains unclear $^{12-15}$.

\section{Objectives}

To evaluate diagnostic accuracy of TcB devices in comparison to total serum bilirubin (TSB) measurements in VLBW neonates.

\section{Method}

This was a time bound prospective cohort study done at the Department of Paediatrics at SSG Hospital and Medical College, Baroda from January to October 2017 after obtaining approval from the Institutional Ethical Committee on Human Research. We included VLBW neonates till 7 days of postnatal age with jaundice. All the VLBW neonates in our study were preterm babies of $\leq 35$ weeks gestational age. Written pre-informed consent was taken from the parents. However, neonates with multiple anomalies incompatible with life, neonates who died within 7 days of birth and those where parental consent to participate was not given, were excluded.

Gestational age was decided by LMP-EDD, and if this was not reliable, then early trimester USG was considered. If no antenatal care was taken or no documents were available, then gestational age was estimated by the "new Ballard score"16. If any VLBW neonate who was part of the study showed signs of jaundice, a serum sample was obtained by heel prick and at the same time (+/-30miutes) $\mathrm{TcB}$ value was obtained by using Drager JM-103 transcutaneous bilirubinometer. Serum sample was processed in microlab's easybili-p instrument which measured serum bilirubin (TSB) by the spectrometric method using $450 \mathrm{~nm}$ and $570 \mathrm{~nm}$ wave length light. As all the neonates were preterm babies of $\leq 35$ weeks, intervention was decided by the gestational age specific National Institute for Health and Care Excellence (NICE) guideline charts. Thereafter, serial monitoring of bilirubin was done by paired readings of TcB and TSB till 7 days of postnatal age. Maximum efforts were done to obtain TSB and TcB readings at the $24^{\text {th }}$ hour of life (HOL), 48 ${ }^{\text {th }} \mathrm{HOL}, 72^{\text {nd }} \mathrm{HOL}, 96^{\text {th }} \mathrm{HOL}, 120^{\text {th }}$ HOL, $144^{\text {th }}$ HOL and $168^{\text {th }}$ HOL. A maximum of 30 minutes was tolerated between TSB and TcB. During phototherapy, an area over the sternum approximately double the size of JM-103 tip was covered with well thickened cotton swabs to keep the area unaffected by phototherapy. A total of 168 neonates were enrolled; however, 128 neonates were considered for statistical analysis as the rest did not have enough readings $(<2)$ for analysis and in some neonates time lag between TcB and TSB was more than 30 minutes. Data analysis was carried out using MedCalc v-17.9.7. Correlation coefficient (r) and Bland Altman plot were done to check diagnostic accuracy of TcB value to TSB.

\section{Results}

A total of 128 neonates with gestational ages of $\leq 35$ weeks and birthweights $\leq 1500 \mathrm{~g}$ were included in the present study. These 128 neonates were subdivided into two groups i) $\leq 1000 \mathrm{~g}$ (18 neonates) and ii) $1001-1500 \mathrm{~g}$ (110 neonates). Gender and gestational age distribution are shown in Tables 1 and 2 .

Table 1: Gender distribution of neonates $(n=128)$

\begin{tabular}{|c|c|c|}
\hline Birth weight (g) & Gender & Number of neonates \\
\hline \multirow{2}{*}{1000} & Male & 06 \\
\cline { 2 - 3 } & Female & 12 \\
\hline \multirow{2}{*}{$1001-1500$} & Male & 53 \\
\cline { 2 - 3 } & Female & 57 \\
\hline
\end{tabular}

Table 2: Gestational age distribution of neonates $(n=128)$

\begin{tabular}{|l|c|c|}
\hline Birth weight (g) & Gestational age (weeks) & Number of neonates \\
\hline \multirow{4}{*}{$\leq 1000$} & $28-30$ & 11 \\
\cline { 2 - 3 } & 31 & 01 \\
\cline { 2 - 3 } & 32 & 02 \\
\cline { 2 - 3 } & 33 & 01 \\
\cline { 2 - 3 } & 34 & 03 \\
\cline { 2 - 3 } & 35 & 00 \\
\hline \multirow{4}{*}{$1001-1500$} & $28-30$ & 17 \\
\cline { 2 - 3 } & 31 & 15 \\
\cline { 2 - 3 } & 32 & 21 \\
\cline { 2 - 3 } & 33 & 27 \\
\cline { 2 - 3 } & 34 & 18 \\
\cline { 2 - 3 } & 35 & 12 \\
\hline
\end{tabular}


Correlation co-efficient (r) value for subgroup i) total 146 and subgroup ii) total 857 paired data of TcB and TSB were collected and analysed and the $r$ value was 0.87 and 0.89 respectively with the $p$ value being $<0.0001$ suggesting statistically significant strong correlation (Table 3, Figure 1).

Table 3: Correlation coefficients (r) of subgroups

\begin{tabular}{|c|c|c|c|c|}
\hline Group & Observations & Number of paired data & 'r' Value & p value \\
\hline \multirow{3}{*}{$\begin{array}{c}\text { Subgroup i) } \\
\text { Birthweight }<1000 \mathrm{~g} \\
n=18\end{array}$} & All the observations & 146 & 0.87 & $<0.0001$ \\
\hline & Before phototherapy & 13 & 0.97 & $\begin{array}{ll}-- \\
\end{array}$ \\
\hline & After phototherapy & 82 & 0.81 & $<0.0001$ \\
\hline \multirow{3}{*}{$\begin{array}{c}\text { Subgroup ii) } \\
\text { Birthweight } 1001-1500 \mathrm{~g} \\
n=110\end{array}$} & All the observations & 857 & 0.89 & \multirow{3}{*}{$<0.0001$} \\
\hline & Before phototherapy & 168 & 0.90 & \\
\hline & After phototherapy & 529 & 0.83 & \\
\hline
\end{tabular}

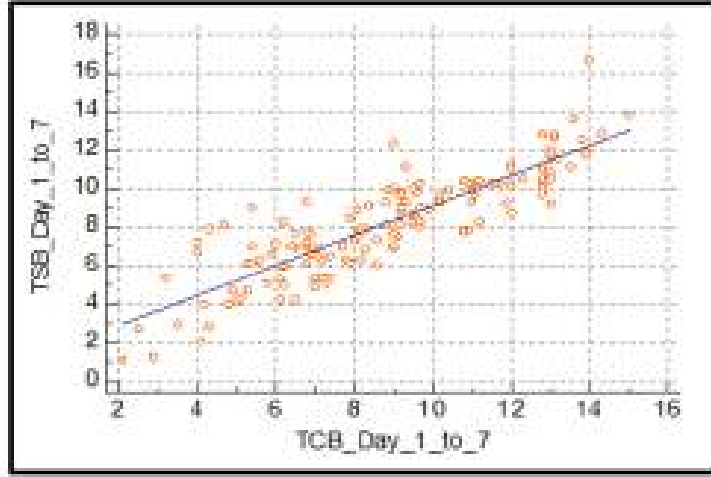

Figure1a: $T C B-T S B$ scatter plot in babies $<1000 \mathrm{~g}$ birth weight showing strong posithe correlation

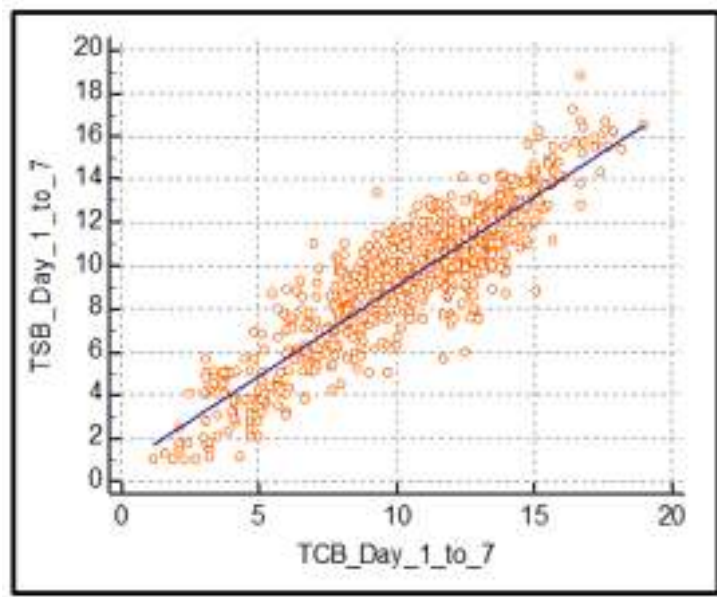

Figure1b: TCB-TSB scatter plot in babies, 1001-1500g birth weight showing strong positive correlation

Data collected before starting phototherapy and after phototherapy were analysed separately for 13 neonates among subgroup i) and 101 neonates among subgroup ii). Correlation co-efficient $r$ values for before phototherapy was 0.97 and 0.90 respectively for subgroup i) \& ii) (Table 3, Figure 2).

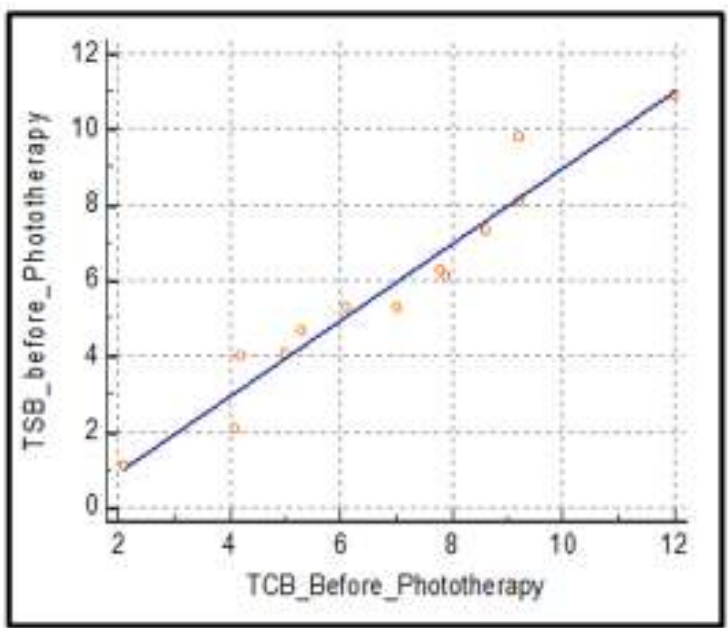

Figure2a: TCB-TSB scatter plot for readings before phototherapy in babies $<1000 \mathrm{~g}$ birth weight showing positive correlation. However, only 13 paired readings were obtained before phototherapy

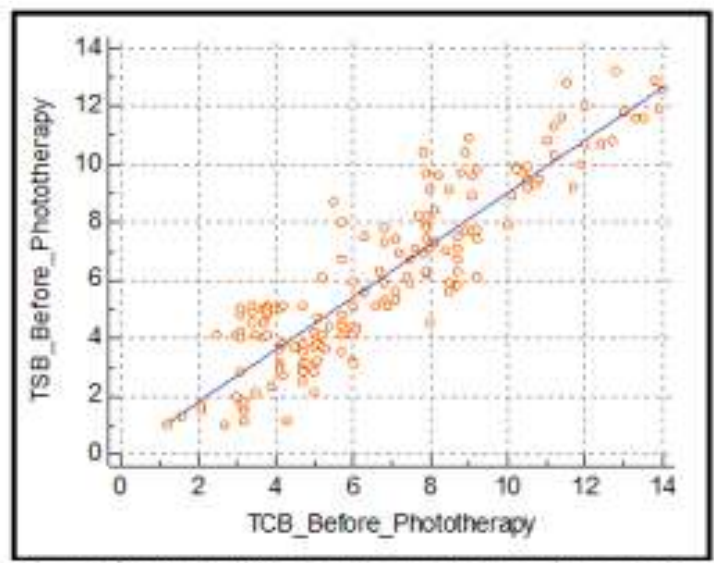

Figure2b: TCB-TSB scatter plot for readings before phototherapy in babies, $1001-1500 \mathrm{~g}$ birth weight showing strong positive correlation

However, for subgroup i) only 13 readings were available and hence more data are required to comment on statistical significance. Correlation coefficient $r$ values for after phototherapy were 0.81 and $0.83, \mathrm{p}$ value being $<0.0001$, for respectively for subgroup i) \& ii) (Table 3 , Figure $3)$. Hence TcB and TSB shows strong correlation in VLBW even after phototherapy. 


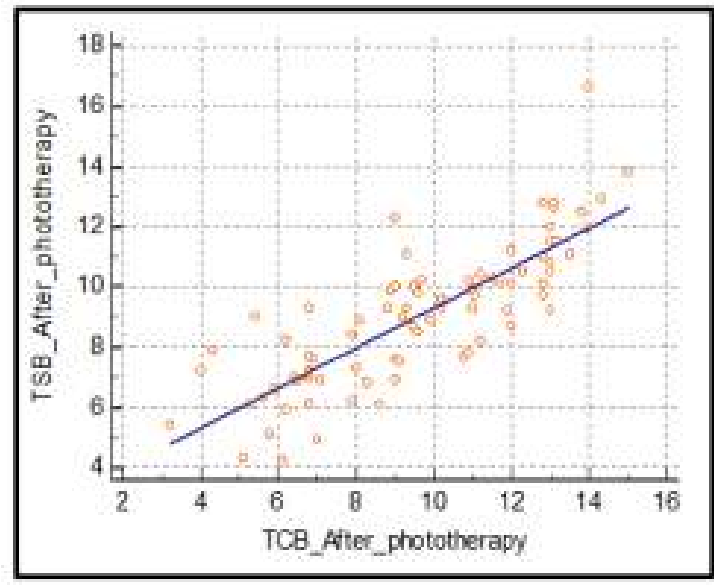

Figure 3a: TCB-TSB scatter plot for readings after phototherapy in babies $<1000 \mathrm{~g}$ birth weight showing positive correlation

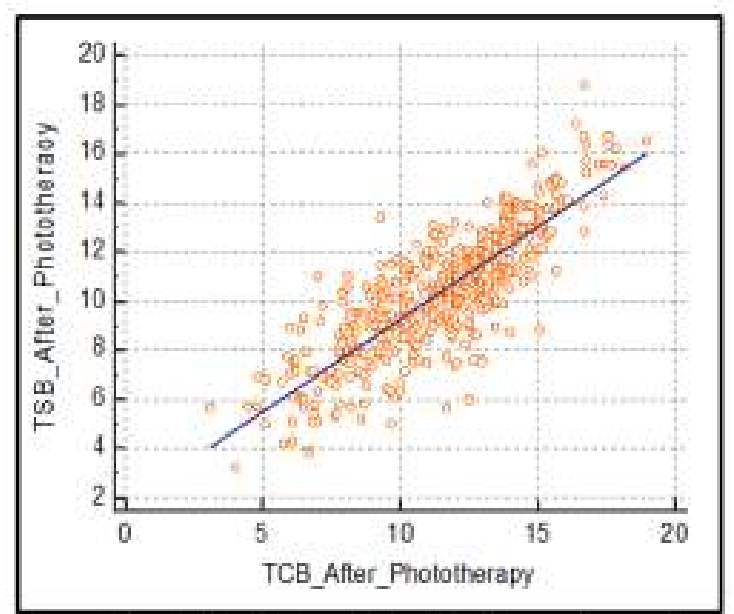

Figure3b: TCB-TSB scatter plot for readings after phototherapy in babies, 1001-1500g birth weight showing strong positive correlation

As Pearson's correlation co-efficient is a poor indicator for agreement between two different methods of bilirubin estimation (i.e. TSB and TcB), we used Bland Altman Plot analysis. Figures 4 and 5 are the Bland-Altman plot analysis for subgroupi) \& subgroup-ii) respectively. These plots are suggestive of a statistically significant $(p<0.0001)$ agreement between TcB and TSB in VLBW preterm neonates, and phototherapy does not affect the agreement.

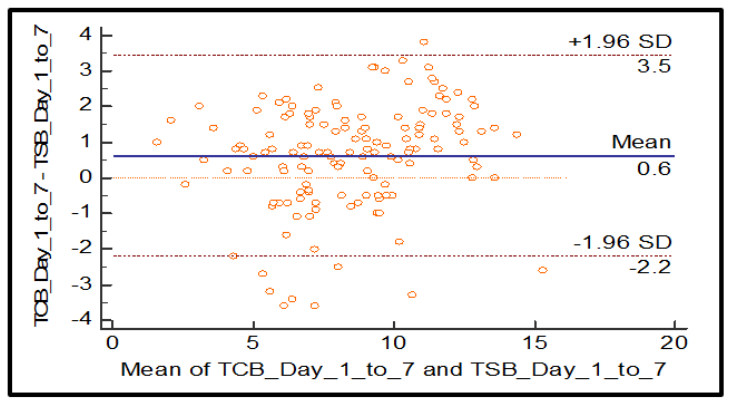

Figure 4a: Bland-Altman plot analysis for babies $<1000 \mathrm{~g}$ for all readings obtained throughout first 7 days of life. The difference of TcB and TSB was $0.63 \mathrm{mg} / \mathrm{dl}$ with SD $1.5 \mathrm{mg} / \mathrm{dl}$ at p-value $<0.0001$, Indicates TcB-TSB approximates each other significantly. Corresponding $95 \%$ limits were $-2.2 \mathrm{mg} / \mathrm{dl} \&+3.5 \mathrm{mg} / \mathrm{dl}$ respectively as shown in figure.

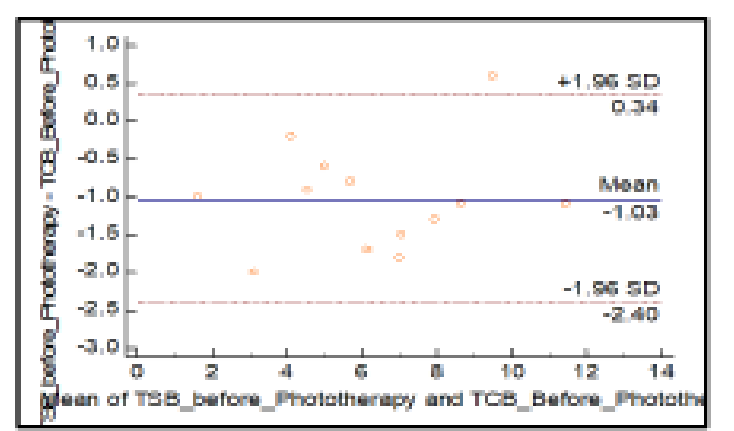

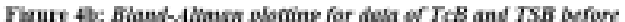

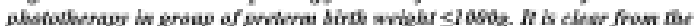

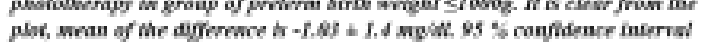

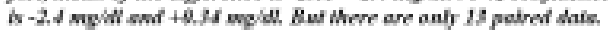

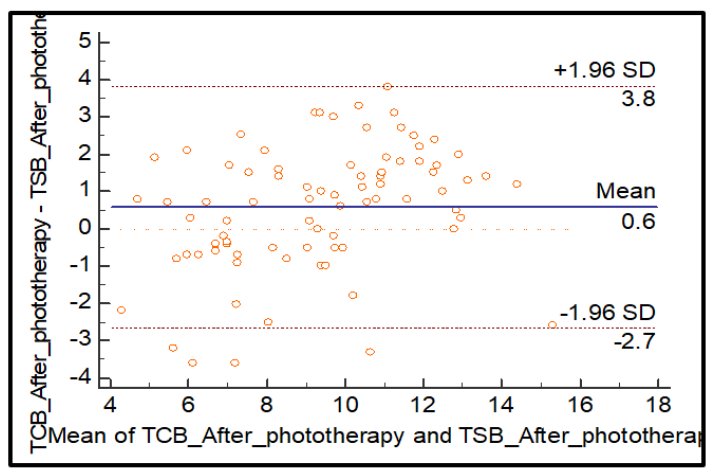

Figure 4c: Bland-Altman plotting for data of TcB and TSB after starting phototherapy in group of preterm birth weight $\leq 1000 \mathrm{~g}$. It is clear from the plot at $p<0.0001$ mean of the difference is $0.6 \pm 1.7 \mathrm{mg} / \mathrm{dl} .95 \%$ confidence interval is - $2.8 \mathrm{mg} /$ dl and $+3.8 \mathrm{mg} / \mathrm{dl}$, indicating there is strong agreement between $T c B$ and TSB after the neonates gets exposed to phototherapy. 

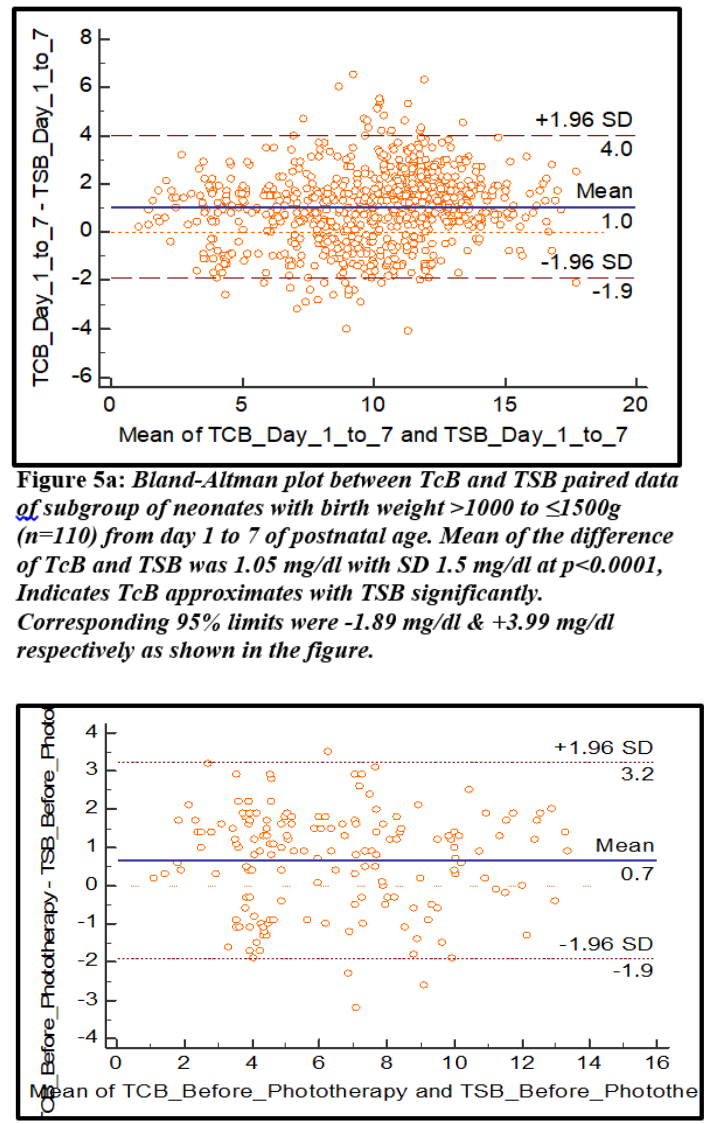

Figure 5b: Bland-Altman plotting for data of TcB and TSB before starting phototherapy in subgroup-ii (birth weight 1001 to $1500 \mathrm{~g}$ ). It is clear from the plot at $p<0.0001$ mean of the difference is $0.66 \pm 1.3$ $\mathrm{mg} /$ dl again indicating TcB approximately equals TSB levels before starting phototherapy as mean of difference is near zero. Agreement starting phototherapy as mean of difference is near zero. Agreement
interval at $95 \%$ is $-1.9 \mathrm{mg} / \mathrm{dl}$ and $+3.2 \mathrm{mg} / \mathrm{dl}$, indicating there is stronger agreement between TCB and TSB before neonates gets phototherapy

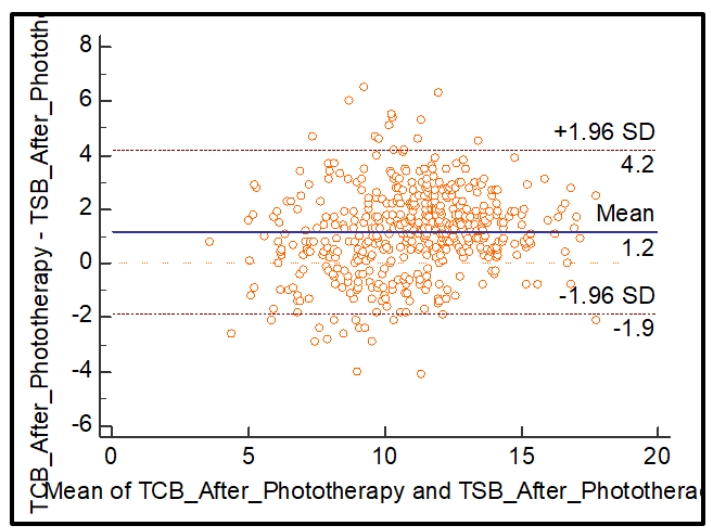

Figure 5c: Bland-Altman plotting for data of TcB and TSB after phototherapy in subgroup-ii (birth weight 1001-1500g). It is clear from plot at $p<0.0001$ mean of the difference is $1.16 \pm 1.5 \mathrm{mg} / \mathrm{dl}$. Agreement interval at $95 \%$ is $-1.86 \mathrm{mg} / \mathrm{dl}$ and $+4.17 \mathrm{mg} / \mathrm{dl}$, indicating there is strong agreement between TCB and TSB after neonates get phototherapy.

\section{Discussion}

The Drager Jaundice Meter-103 assesses yellowness of neonatal subcutaneous tissue by measurement of the difference between optical densities for light in the blue and green wavelength areas. As this optical density difference demonstrates a linear correlation with the SB concentration, it is converted into TSB and indicated digitally ${ }^{18}$. Advantages of this noninvasive technique are real-time results, costefficacy and avoidance of pain and local infection. Drager JM-103 TcB assessment can be used to identify the need for blood sampling for TSB levels in term and near-term neonate ${ }^{2,18,19}$. For the preterm infant current evidence is controversial. Several previous studies were done with various results and correlation coefficients ranged from 0.68 to $0.96^{12,13,20}$.

In a study by Bhutani et $a l^{1}$ there was a strong correlation between $\mathrm{TcB}$ and TSB in $>2500 \mathrm{~g}$ neonates. Negar et $a l^{21}$ estimated $\mathrm{r}$ value which was 0.83 in $>2500 \mathrm{~g}$ neonates. However, $\mathrm{r}$ values estimated in VLBW neonates in 2009 by Karolayi et $a l^{20}$, Sui ly et $a l^{22}$, Stillova et $a l^{23}$ suggest that there is strong correlation among VLBW neonates also. In our study we found that there is a strong correlation between TcB and TSB in VLBW neonates and this correlation is not affected even after phototherapy. In our study, we found that there is a statistically significant agreement between TcB and TSB in VLBW neonates as well and that phototherapy did not affect this agreement.

\section{Conclusions}

$\mathrm{TcB}$ measurements correlate significantly with TSB levels in early preterm neonates with VLBW. Phototherapy does not affect the correlation significantly.

\section{References}

1. Bhutani VK, Gourley GR, Adler S, Kreamer B, Dalin C, Johnson LH. Noninvasive measurement of total serum bilirubin in a multiracial predischarge newborn population to assess the risk of severe hyperbilirubinemia. Pediatrics 2000; 106(2):E17.

https://doi.org/10.1542/peds.106.2.e17

PMid: 10920173

2. Maisels MJ, Ostrea EM, Touch S, Clune SE, Cepeda E, Kring E, et al. Evaluation of a new transcutaneous bilirubinometer. Pediatrics 2004; 113(6):1628-35. https://doi.org/10.1542/peds.113.6.1628 PMid: 15173483

3. Maisels MJ, Kring E, Rolinski B, Kreamer B, Dalin C, Johnson L. Transcutaneous bilirubinometry decreases the need for serum bilirubin measurements and saves money. Pediatrics 1997; 9(4):599. https://doi.org/10.1542/peds.99.4.599 PMid: 9093305 
4. Moyer VA, Ahn C, Sneed S. Accuracy of clinical judgment in neonatal jaundice. Archives of Pediatrics and Adolescent Medicine 2000; 154(4):391-4.

https://doi.org/10.1001/archpedi.154.4.391 PMid: 10768679

5. Szabo P, Wolf M, Bucher HU, Haensse D, Fauchère JC, Arlettaz R. Assessment of jaundice in preterm neonates: comparison between clinical assessment, two transcutaneous bilirubinometers and serum bilirubin values. Acta Paediatrica 2004; 93(11):1491-5. https://doi.org/10.1111/j.16512227.2004.t b02635.x

PMid: 15513578

6. Anand KJS. Pain, plasticity, and premature birth: a prescription for permanent suffering? Nature Medicine 2000; 6(9):971-3.

https://doi.org/10.1038/79658

PMid: 10973310

7. El-Beshbishi SN, Shattuck KE, Mohammad AA, Petersen JR. Hyperbilirubinemia and transcutaneous bilirubinometry. Clinical Chemistry 2009; 55(7):1280-7.

https://doi.org/10.1373/clinchem.2008.121 889

PMid: 19443565

8. Schmidt ET, Wheeler CA, Jackson GL, Engle WD. Evaluation of transcutaneous bilirubinometry in preterm neonates. Journal of Perinatology 2009; 29(8):5649.

https://doi.org/10.1038/jp.2009.38

PMid: 19322191

9. Kazmierczak SC, Robertson AF, Briley KP, Kreamer B, Gourley GR. Transcutaneous measurement of bilirubin in newborns: comparison with an automated Jendrassik-Grof procedure and HPLC. Clinical Chemistry 2004; 50(2):433-5.

https://doi.org/10.1373/clinchem.2003.027 326

PMid: 14752014

10. Rubaltelli FF, Gourley GR, Loskamp N, Modi N, Roth-Kleiner M, Sender A, et al. Transcutaneous bilirubin measurement: a multicenter evaluation of a new device. Pediatrics 2001; 107(6):1264-71. https://doi.org/10.1542/peds.107.6.1264

PMid: 11389241

11. American Academy of Pediatrics Subcommittee on Hyperbilirubinemia. Management of hyperbilirubinemia in the newborn infant 35 or more weeks of gestation. Pediatrics 2004; 114(1):297316.

https://doi.org/10.1542/peds.114.1.297

PMid: 15231951

12. Nanjundaswamy S, Petrova A, Mehta R, Bernstein W, Hegyi T. The accuracy of transcutaneous bilirubin measurements in neonates: A correlation study. Neonatology 2004; 85(1):21-5. https://doi.org/10.1542/peds.114.1.297 PMid: 15231951

13. Namba F, Kitajima H. Utility of a new transcutaneous jaundice device with two optical path in premature infants. Pediatrics International 2007; 49(4):497501.

https://doi.org/10.1111/j.1442200X.2007.0

2386.x

PMid: 17587275

14. Knüpfer M, Pulzer F, Braun L, Heilmann A, Robel-Tillig E, Vogtmann C. Transcutaneous bilirubinometry in preterm infants. Acta Paediatrica 2001; 90(8):899-903.

https://doi.org/10.1111/j.16512227.2001.t b02454.x

PMid: 11529539

15. De Luca D, Zecca E, de Turris P, Barbato G, Marras M, Romagnoli C. Using BiliCheck for preterm neonates in a subintensive unit: diagnostic usefulness and suitability. Early Human Development 2007; 83(5):313-7.

https://doi.org/10.1016/j.earlhumdev.2006. 06.006

PMid: 16949773

16. Limawal F, Madjid DA, Daud D. The accuracy of determining newborn's maturity between New Ballard's score, Ballard's score, and first day of last menstrual period. Paediatrica Indonesia 2008; 48(2):59. https://doi.org/10.14238/pi48.2.2008.5963 
17. Bland JM, Altman DG, Martin Bland J, Altman DG. Statistical methods for assesing agreement between two methods of clinical measurement. Lancet 1986; 1(8476): 307-10.

https://doi.org/10.1016/S01406736(86)908 $37-8$

18. Yasuda $\mathrm{S}$, Itoh $\mathrm{S}$, Isobe $\mathrm{K}$, Yonetani $\mathrm{M}$, Nakamura $\mathrm{H}$, Nakamura $\mathrm{M}$, et al. New transcutaneous jaundice device with two optical paths. Journal of Perinatal Medicine 2003; 31(1):81-8.

https://doi.org/10.1515/JPM.2003.012

PMid: 12661149

19. Sanpavat S, Nuchprayoon I. Transcutaneous bilirubin in the pre-term infants. Journal of the Medical Association of Thailand 2007; 90(9):1803-8.

20. Karolyi L, Pohlandt F, Muche R, Franz AR, Mihatsch WA. Transcutaneous bilirubinometry in very low birthweight infants. Acta Paediatrica 2004; 93(7):941-4.

https://doi.org/10.1111/j.16512227.2004.t b02693.x

PMid: 15303810
21. Sajjadian N, Shajari H, Saalehi Z, Esphahani F, Taheri PA. ORIGINAL REPORT Transcutaneous bilirubin measurement in preterm neonates. Acta Medica Iranica 2012; 50(11):765-70.

22. Siu LY, Siu LW, Au SK, Li KW, Tsui $\mathrm{TK}$, Chang YY, et al. Evaluation of a transcutaneous bilirubinometer with two optical paths in Chinese preterm infants. Hong Kong Journal of Paediatrics 2010; 15:132-40.

23. Stillova L, Matasova K, Zibolen M, Stilla J, Kolarovszka H. Transcutaneous bilirubinometry in preterm neonates. Indian Pediatrics 2009; 46(5):405-8. 